\title{
PROGRESSO TÉCNICO E TRABALHO MIGRANTE NO SETOR SUCRO-ALCOOLEIRO DA REGIÃO DE RIBEIRÃO PRETO
}

Francisco Alves*

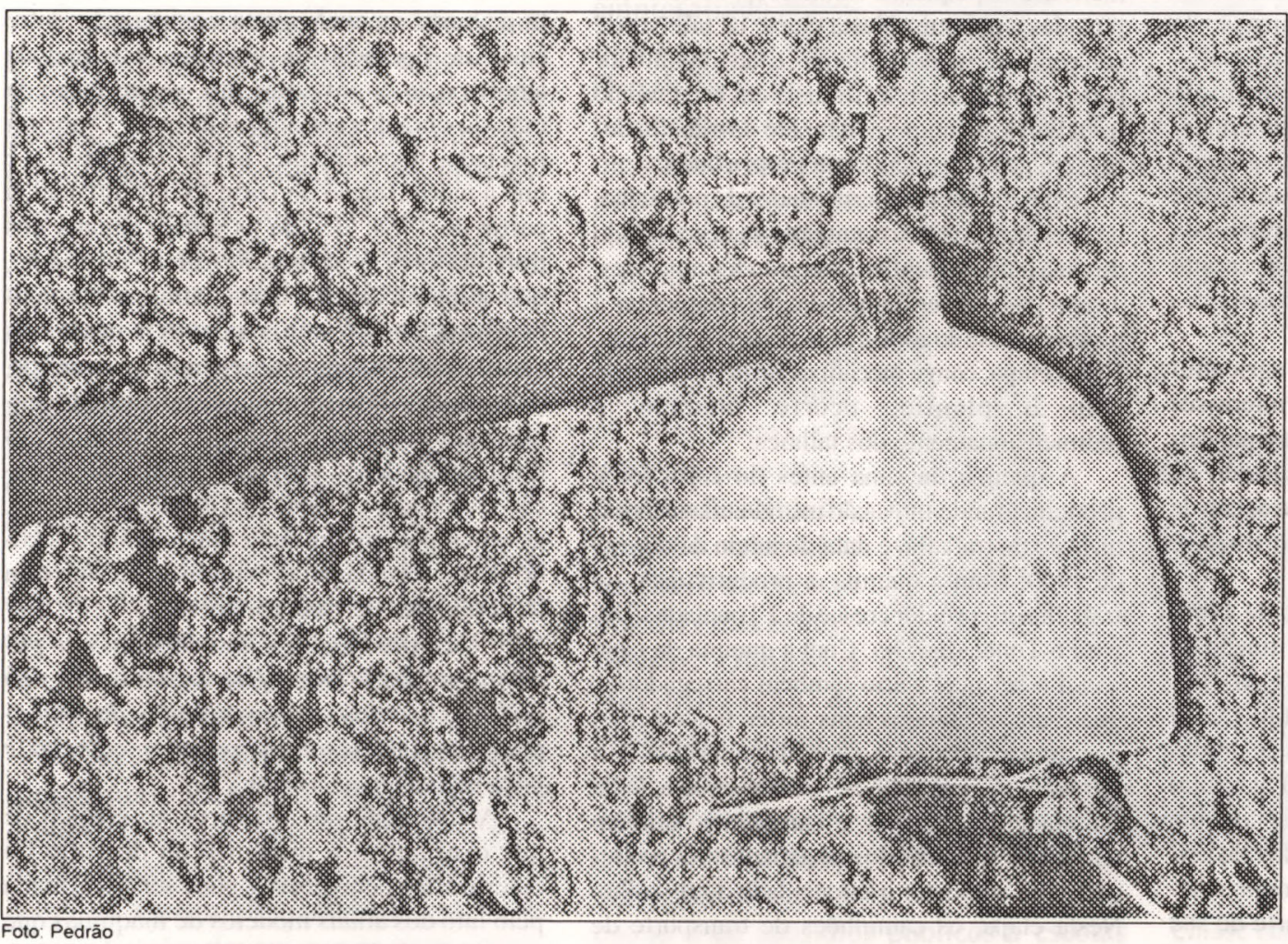

\section{Introdução}

Todos os anos na safra de cana-de-açúcar aflui para a região de Ribeirão um grande número de trabalhadores migrantes. São trabalhadores de diferentes regiões que vêm em busca de trabalho. Alguns têm neste trabalho a oportunidade de complementar a renda e garantir a sua reprodução como pequenos produtores em suas regiões de origem. Para outros, a migração é uma forma de busca de outras condições de reprodução, para viabilizar a sua mudança "definitiva" em outromomento. Para outros, ainda, é uma viagem sem volta, vêm e ficam, trazem as esposas, noivas e nunca mais retornam. Existem outros casos de trabalhadores que vêm uma única vez e não voltam mais no ano seguinte. Estes trabalhadores são em grande parte provenientes de regiões nas quais a reprodução se dá em condições difíceis, quer pela escassez de trabalho, quer pelas dificuldades de manterem-se como produtores independentes, devido à impossibilidade de acesso à terra para reproduzirem-se autonomamente. Estes trabalhadores são mineiros, em geral do grande Vale do Jequitinhonha, da Bahia, de outros estados do Nordeste, etc., mas são também paranaenses, matogrossenses e até de outras cidades do Estado de São Paulo.

Há uma enorme dificuldade em saber qual o número e de onde exatamente provêm estes trabalhadores. Há total escassez e falta de informações confiáveis sobre as dimensões do trabalho migrante no Brasil. Apenas se sabe que existem e que no período da safra as pensões, os muquifos, os alojamentos das próprias empresas e as casas da periferia são ocupadas por estes trabalhadores. Alguns vêm por conta própria, outros foram contratados na própria região de origem, quer por um empreiteiro (gato), quer por um trabalhador como eles com contato regular em alguma usina, ou fornecedor de cana. Alguns vão direto para os alojamentos das usinas e outros vão para pensões e muquifos. Outros ainda vão provisoriamente para casas de parentes e amigos, até que consigam emprego. Outros reúnem-se em grupos, em geral compostos de primos, parentes e amigos da mesma cidade e alugam uma casa, constituindo uma "república", tornando-se "queima-lata" (trabalhadores que preparam em casa sua própria comida).

Dada esta diversidade de situações e de locais de origem e de formas de viagem e contratos de trabalho, qualquer tentativa de generalização sobre os migrantes enfrenta o enorme risco de tornar-se ineliciente para caracterizar este importante contingente de trabalhadores.

O objetivo deste artigo é mostrar as características do progresso técnico no setor sucroalcooleiro, para refletir sobre os seus efeitos para este enorme contingente de trabalhadores que todos os anos chega à região de Ribeirão Preto.

\section{Características do Padrão Tecnológico}

O padrão de desenvolvimento tecnológico da agricultura brasileira foi definido, em suas 
linhas centrais, na década de 1960, com a articulação, num mesmo projeto, dos interesses da burguesia industrial, nacional e internacional, com os interesses dos setores modernos, ou com possibilidade de modernização, da agricultura brasileira. Esta articulação se concretiza com o golpe de 1964, que vai, ao longo do seu curso, selando um pacto entre estes setores e sepulta, de certa forma, as reivindicações populares, do período anterior, por democracia e distribuição de renda, que passavam pela necessidade de Reforma Agrária.

O Sistema Nacional de Crédito Rural foi o principal instrumento de política para obter-se, simultaneamente, crescimento econômicoemodernização conservadora da agricultura. Este possibilitou as mudanças na base técnica de produção, que intensificaram a organização do processo produtivo agrícola em bases capitalistas avançadas, culminando com uma integração verticalizada, agricultura/indústria, sobcomando desta última. Neste processo, teve papel importante o cunho conservador e parcial das políticas modernizantes, que concentrou renda em ramos específicos e viabilizou o capital necessário para parte dos agentes econômicos e sociais envolvidos.

O processo de modernização da agricultura, ao promover a articulação de interesses industriais e agrícolas com o sistema financeiro, possibilitou uma crescente integração de capitais, que tornou a agricultura uma opção de investimento dentro da lógica da valorização e acumulação de capital.

Nesta lógica, no final da década de 1960, dá-se um passo importante na constituição do chamado Complexo Agro-Industrial (CAI)Brasileiro. Este se caracteriza pela constituição de um setor industrial produtor de bens de produção para a agricultura (chamado de $D_{1}$ agricola) e consolidação em bases modernas de um mercado de produtos industrializados de origem agropecuária, constituindo-se num sistema de agroindústrias, que dirige parte de sua produção para o mercado interno e parte para o mercado externo.

O setor sucro-alcooleiro será um dos que consegue mais rapidamente constituir um CAI completo, articulado ao setor industrial, tanto à montante, quantoà jusante da produção agrícola.

O Estado de São Paulo torna-se, neste processo, além do principal produtor de açúcar e álcool, o que mais rápida e solidamente constitui o CAI sucro-alcooleiro. A partir do Estado de São Paulo este processo se expande para outros Estados e Regiões, como o Sul de Minas, Norte do Paraná, o Mato Grosso do Sul, as Regiões de tabuleiro do Nordeste, que guardadas suas especificidades, adotarão o padrão tecnológico de produção de açúcar e álcool de São Paulo' .

\section{A Mecanização do Corte de Cana}

A colheita de cana compreende três fases interdependentes: o corte, o carregamento e o transporte até a usina. $\Lambda$ mecanização da colheita de cana se dá lentamente, atinge primeiro o transporte, com o desenvolvimento de caminhões cada vez maiores e mais adaptados ao transporte de cana. Posteriormente, a mecanização atinge o carregamento.

Até a década de 1950, o trabalhador cortava e enfeixava a cana, amarrando os fardos com as folhas, quando era executado o corte da cana crua, sem queimar. Esta cana cortada e enfeixada era transportada nas costas dos homens até os pequenos caminhões, ou carroças puxadas a animais. Nesta etapa, os talhões de cana eram de menor tamanho, cada trabalhador cortava em duas ou três ruas e em cada talhão trabalhava um número reduzido de trabalhadores, em geral residentes na propriedade.

Com o aumento das unidades de produção, na década de 1960, e o aumento da necessidade de cana para alimentar estas grandes unidades, a cana passa a ser queimada, para aumentar a produtividade docorte já não é mais enfeixada. Nesta etapa, com a mecanização do preparo do solo e plantio, ocorre também o redimensionamento dos talhões.

A queima da cana antes do corte foi a primeira grande inovação introduzida na organização do trabalho e data do início da década de 1960. Com a queima, a produtividade do trabalho do cortador cresce de 2 Toneladas/Dia para 6 Toneladas/Dia. Com a queima da cana passa a ser necessário também carregadores, que eram os homens mais fortes fisicamente, que transportavam a cana desamarrada e a atiravam nos caminhões ${ }^{2}$. Com a separação da atividade do cortador e carregador também passa a ser introduzido o pagamento por produção, para aumentar a intensidade do trabalho. Nesta etapa, os caminhões de transporte de cana também cresceram de tamanho para transportar uma quantidade maior de cana.

Na etapa seguinte, final da década de 60, os carregadores foram substituidos pelos guinchos mecânicos ${ }^{3}$, que empilham e carregam a cana do chão para as carrocerias dos caminhões, que também cresceram em tamanho e passaram a levar, em alguns casos, um ou dois reboques: os famosos "Romeus e Julietas" ou "'triminhões'

No corte de cana, o trabalhador ainda detém o controle do seu processo de produção, porque o ritmo e a intensidade do trabalho ainda são determinados por ele, devido a sua habilidade e destreza. Os capitalistas interferem na intensidade, condicionando o pagamento à produção diária. Porém, é um controle uma subordinação - apenas formal, porque é mediada pela forma de pagamento.

Com a introdução do corte mecânico de cana, ocorre a substituição do trabalhador pela máquina, e esta é antecedida pelo cálculo comparativo entre custo de operação da máquina e o salário pago por unidade colhida, como em qualquer unidade de produção capitalista. Porém, o que se percebe, no caso da Região de Ribeirão Preto, é que este cálculo não foi determinante para a introdução e, principalmente, para a ênfase de mecanizar o corte de cana, observadas após $1984^{4}$.

Através de entrevistas, realizadas com uma série de usineiros da Região de Ribeirão Preto, ficou claro que a decisão de mecanizar o corte de cana não foi tomada unicamente com base na viabilidade econômica da mecanização, frente ao corte manual, numa comparação entre custo de operação da máquina e tempo de amortização do investimento, versus custo da mão-de-obra dos cortadores de cana. O que foi revelado, textualmente, nestas entrevistas, é que a mecanização do corte foi incentivada, a partir de 1984, devido às greves anuais dos trabalhadores assalariados rurais da região, que ao paralisarem o corte, paralisavam também as usinas. Nestas condições, a mecanização do corte de cana era, segundo os usineiros, a forma de adquirirem maior poder de barganha para negociar a pauta de reivindicações dos trabalhadores, sem as unidades de produção paralisadas. Com a mecanização do corte, as usinas podem continuar funcionando, moendo a cana cortada pelas máquinas, mesmo com os cortadores de cana em greve.

"Os trabalhadores descobriram que podem parar as usinas e fizeram isıo. Nós não podemos deixar as usinas nas mãos dos trabalhadores, que resolvem parar a colheita $e$ param tambèm as usinas" ".

A revelação dos usineiros no sentido de que o incentivo à mecanização do corte foi determinada pelas greves, pode ser confirmada pelo fato dos atuais modelos de máquinas que permitiram baixar os custos do corte mecânico, já estavam disponíveis ao setor desde o final da década de 70. Além disto, a Região do Estado de São Paulo que mais mecanizou o corte foi a de Ribeirão Preto, exatamente a Região na qual é maior o grau de organização e luta dos trabalhadores rurais. Em outras regiões do Estado com o mesmo ritmo de incorporação do progresso técnico, mas onde não há greves, a colheita permaneceu manual.

É evidente que a decisão de mecanizar leva em consideração a análise financeira de custos diferenciais, própria à atividade capitalista. Porém, pelo exposto, estas não são, ou não foram determinantes da decisão de mecanizar o corte na Região de Ribeirão Preto. O determinante foi o grau de organização e luta dos trabalhadores, ao realizarem greves anuais 


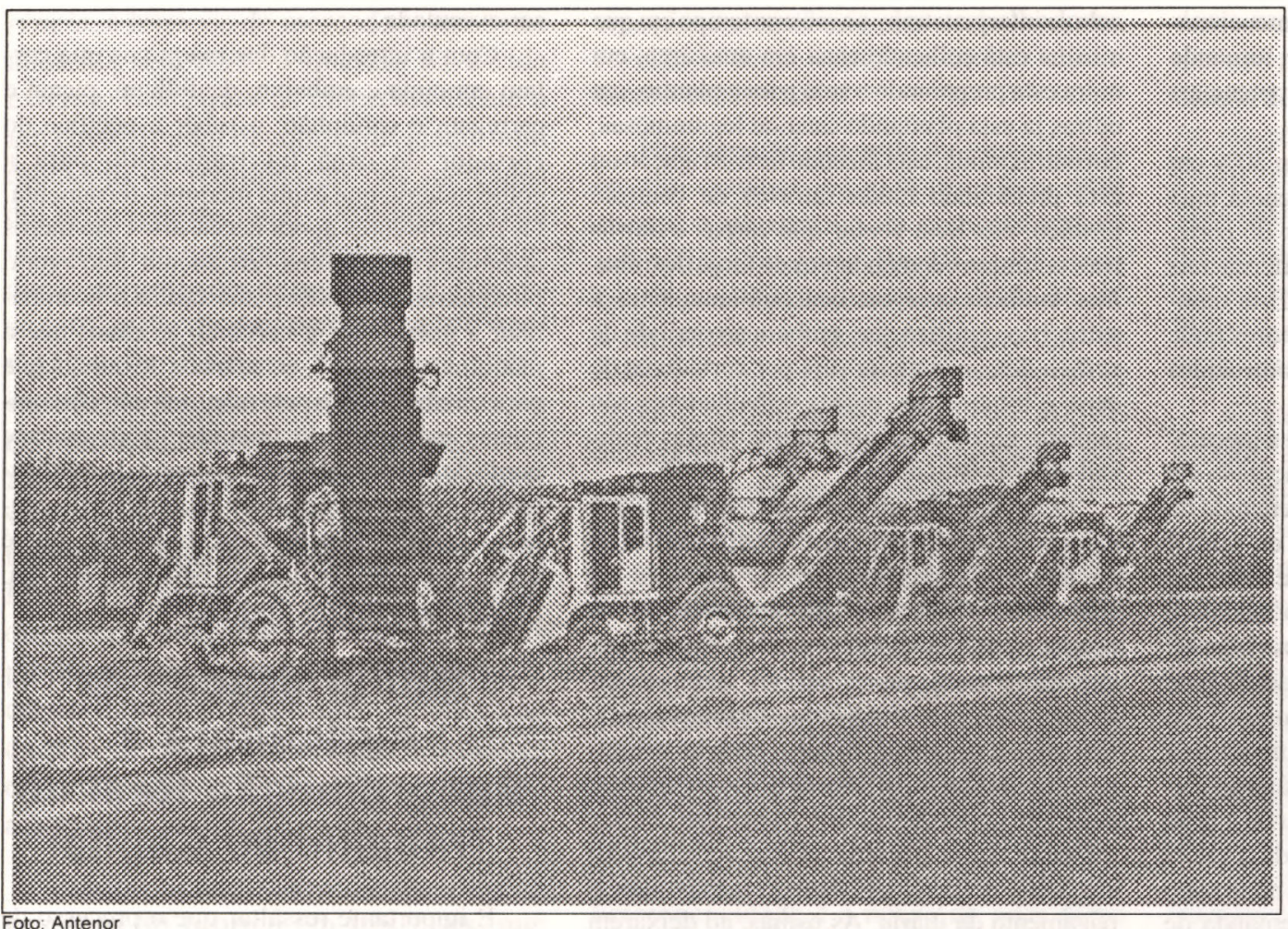

diferenças de custo do corte mecânico em relação ao manual. As novas máquinas desenvolvidas ao final da década, passaram a cortar cana em pé ou cana acamada (deitada) e ainda cortar e picar cana e já depositá-la diretamente no caminhão. Dessa forma, essas novas máquinas substituíram as carregadeiras de cana.

Essas novas máquinas colheitadeiras de cana permitiram elevar a produtividade das máquinas de 20 toneladas por hora em 1976 para 41 toneladas por hora, em 1980 e 60 a 80 toneladas/hora atualmente? Ao mesmo tempo, a diferença de custo do corte mecânico, em relação ao manual, elevou-se de 7,2\% em 1976, observado por GRAZIANO DA SILVA, para cerca de $30 \%$, atualmente ${ }^{8}$.

Ao mesmo tempo, a melhoria de performance não se deveu apenas a melhorias técnicas das máquinas, mas à incorporação de toda uma infra-estrutura de apoio à mecanização do corte, que vai de

por melhorias de suas condições de vida e trabalho.

A colheita mecanizada de cana-de-açúcar pressupõe uma série de modificações técnicas, que vão desde o plantio até o recebimento da cana por parte da usina. Apesar dos melhoramentos técnicos ocorridos nas máquinas, desde a sua introdução no Brasil, ainda continuam existindo certas limitações técnicas intransponíveis para a mecanização do corte, tais como a declividade. Os demais limites técnicos vêm sendo gradativamente corrigidos pelos novos modelos de máquinas, postos à venda no mercado, que incorporaram melhoramentos sugeridos pelos próprios departamentos de manutenção mecânica das usinas. Mas a correção destes limites exige, por outro lado, vultosos investimentos, que não são acessiveis a todos os produtores: redimensionamento dos talhões; modificações no espaçamento e correção das falhas do terreno, etc.

As primeiras máquinas introduzidas no país datam do final da década de 1960. Estas máquinas cortavam cana inteira e a depositavam, em sentido transversal, nas linhas. Embora essas máquinas já apresentassem custos inferiores em 7,2\% ao corte manual, de acordo com dados de 1976 da Copersucar, frente aos salários baixos dos cortadores, a sua utilização ainda estava restrita a um número pequeno de produtores, que as utilizavam somente no início da safra para diminuir os salários. Eram, o que GRAZIANO DA SILVA (1980) chama de máquinas de "vitrine", pois entravam em operação ao início da safra e em seguida eram substituídas pelos cortadores e postas de volta na vitrine.

Nesta etapa, início da década de 1970, o incentivo à mecanização do corte se devia a perspectivas pessimistas quanto a existência, no Estado de São Paulo, de contingente de trabalhadores assalariados temporários, capaz de dar conta do corte sem pressionar os salários para cima. Porém o processo de modenização da agricultura, no Brasil, e a dinâmica populacional se encarregaram de resolver o problema, pondo à disposição do setor um enorme contingente de trabalhadores, nas cidades dormitórios da Região; contingente esse anualmente acrescido de um elevado número de trabalhadores vindos de várias partes do pais, principalmente do Vale do Jequitinhonha, que afluem à Região e pressionam os salários para baixo ${ }^{6}$. Isto significa, que o incentivo à mecanização pela falta de braços para o corte, com a consequente tendência à elevação dos salários, já não se verifica. Daí, o estímulo à mecanização existente, na década de 80 , deve ser buscado em outro fator, que não o da escassez de trabalhadores.

A partir de 1975, com o Pró-álcool e o crescimento da lavoura em novas áreas, o interesse pela mecanização foi renovado. Entraram em cena novos fabricantes de colheitadeiras de cana (Dedini e Santal), produzindo novos modelos, desenvolvidos a partir de modelos importados, que elevaram ainda mais a performance das máquinas e ampliaram as caminhões oficina, com peças de reposição para consertos das máquinas no próprio campo, caminhões pipas, caminhões comboio com combustivel e lubrificante, para manter a máquina operando continuamente, em alguns casos, 24 horas por dia. As usinas, para introduzirem a mecanização do corte, tiveram que efetuar modificações nos caminhões de transporte de cana, que tiveram de ser adaptados para o recebimento de cana picada, e tiveram que introduzir modificações no recebimento de cana na usina.

A incorporação de toda esta infra-estrutura de apoio, envolvendo novos equipamentos e homens, as modificações no campo e nas usinas, ao mesmo tempo que aumentou a produtividade das máquinas, aumentou bastante a necessidade de capital imobilizado pelas usinas, que só é acessivel a um número pequeno de grandes usineiros. Em 1980, verificou-se que o rendimento médio de uma colhedeira de cana atinge 200 toneladas por dia em 10 horas de trabalho, substituindo aproximadamente 30 homens/dia, com produção superior a 6 toneladas/dia. Levando-se em consideração a possibilidade de financiamento da máquina a juros subsidiados, existentes naquele período, a viabilização financeira do investimento só seria possível para propriedades com área a ser trabalhada superior a $864 \mathrm{ha}^{9}$. Utilizando-se a mesma metodologia de Kageyama (1981), verificamos que hoje, sem financiamento, a área necessária para viabilizar o investimento se elevou para mais de $1050 \mathrm{ha}^{10}$. Se for levado em 
consideração toda a infra-estrutura mencionada acima, esta área se eleva bastante, tornando ainda mais restrito o número de potenciais utilizadores do corte mecânico.

A redução de custos, situada em $30 \%$ em média, com um pico de $50 \%$, já denota uma tendência clara para a mecanização do corte, pois permite a obtenção de custos diferenciais de produção bastante expressivos. Esta redução de custos é significativa para setores onde onde os preços são tabelados e controlados como o sucro-alcooleiro.

O objetivo dos capitalistas não é a mecanização do corte; esta deve ser incrementada até atingir o nível de estabilização da demanda de força de trabalho entre os períodos de safra e entressafra. Isto é, o que se pretende é trabalhar o ano inteiro com o mesmo número médio de trabalhadores, que atendam às necessidades de trabalho das usinas tanto no período de pico (safra) quanto no período de contra-pico (entressafra). A etapa do plantio, embora seja motomecanizada, ainda exige um número elevado de trabalhadores, porém, menor do que na safra. Neste sentido, a mecanização do corte da cana torna a necessidade de braços no plantio e tratos culturais o horizonte da demanda de trabalhadores para os dois períodos: safra e entressafra. Isto significa que os usineiros, com a mecanização do corte, têm a sua demanda por força de trabalho nivelada por baixo e passam a atender, de forma perversa, uma atinga reivindicação dos trabalhadores assalariados rurais: contrato de trabalho o ano inteiro e não apenas na safra.

A estabilização da demanda de trabalhadores em um nível médio, que atenda tanto as necessidades de braços na safra quanto na entressafra, tem duas explicações: possibilidade de realização de uma melhor seleção e redução de encargos no contrato de safristas. A redução da demanda por força de trabalho põe à disposição das usinas um amplo contingente de trabalhadores, que pode assim ser melhor selecionado. Esta seleção, ao ser mais rigorosa, pode privilegiar aspectos menos técnicos e mais disciplinares e "ideológicos"

O contrato de trabalhadores safristas, embora seja interessante, por parte das usinas, dado a dinâmica da produção agrícola, com picos bem marcados de demanda de trabalhadores, propiciada pelo processo de modernização da agricultura, foi duramente golpeado, quando os trabalhadores passaram a exigir e conquistaram, em várias empresas, o contrato diretamente pelas usinas e não mais pelos "gatos". O contrato de trabalho regular do safrista onerou as empresas com pagamento dos encargos trabalhistas, fundamentalmente a indenização pelo fim da safra.

Como a colheita de cana é longa, mais de 8 meses por ano, várias atividades do ciclo agrí- cola se interpenetram: ao mesmo tempo em que a usina está colhendo cana em uma área, em outra está preparando o solo para o plantio, em outras já está plantando cana ou leguminosas, em outras ainda, está fazendo ferti-irrigação ou está preparando mudas através de controle térmico, etc. Sem contar que carpas e outros tratos culturais demandantes de força de trabalho, também ocorrem concomitantemente à safra. Isto significa que, embora no período de safra a demanda maior seja por cortadores de cana e bituqueiros, outros trabalhadores são também necessários para outras tarefas realizadas ao mesmo tempo.

O expediente utilizado pelas usinas que mecanizaram o corte, e nivelaram a utilização de força de trabalho entre os períodos de entressafra e safra, tem sido no sentido de: a) ocupar os trabalhadores em outras atividades, que não o corte, reservando os melhores talhões, - com cana mais ereta, terrenos menos íngremes e cana mais limpa -, para as máquinas, deixando aos cortadores os piores talhões, onde a sua produtividade por dia é mais baixa, eb) empregar os traballadores no corte, por dia em áreas de cana suficientes apenas para o pagamento da diária. As usinas, ao deixarem aos trabalhadores as piores áreas de cana, deixam também, frequentemente, uma quantidade de cana insuficiente para o trabalhador alcançar a média de corte na Região. Esta prática além de reduzir o número de trabalhadores reduziu o salário de cada um deles e o dispêndio das usinas.

Assim, através da mecanização, o perfil de demanda de força de trabalho para as usinas, mudou. Isto é, não é mais necessário empregar, na colheita, trabalhadores bons de corte, poréın ruins em outras atividades. Passa a ser necessário um trabalhador apto à realização de todas as atividades agrícolas necessárias à produção de cana. Antes da mecanização do corte, os trabalhadores mais fortes iam para o corte de cana, os mais fracos para a bituca, apanha da cana; os demais iam para a laranja ou o café. Para trabalhar no corte de cana, as usinas, através dos "gatos", selecionavam os mais fortes.

A atividade de corte de cana necessita, além de resistência física, de uma certa especialização, que é o manejo do podão: para cortar em baixo, rente ao solo e em cima, junto ao palmito; desfolhar e amontoar cana. A primeira vista, o corte de cana parece ser uma atividade simples, que qualquer um pode executar. Na realidade, a tarefa é simples, porém, na velocidade requerida pelo corte, toma-se complexa, pois exige um conjunto de movimentos e golpes sincronizados, que nem todos os trabalhadores conseguem executá-lo satisfatoriamente. $\mathrm{O}$ corte de cana é diferente de uma atividade que só requeira força física para ser executada

Com a introdução das máquinas que cortam em cima e embaixo, desfolham, picam e carregam o caminhão, o saber específico do cortador de cana foi transferido para a colheitadeira, que é uma máquina-ferramenta. Os trabalhadores agora necessários são meros apêndices da máquina-ferramenta. São agora, bituqueiros-cortadores, sua tarefa é acompanhar a máquina e ir cortando as canas que a máquina não cortou, ou os bicos de talhão, que para serem cortados pela máquina exigem complexas manobras do operador, com enorme perda de tempo e elevado consumo de combustível. Esses novos personagens também executam as tarefas básicas dos bituqueiros, que é cortar as canas que ficaram para trás, ou seja, a tarefa acessória da máquina.

\section{Modernização da Agricultura e Subordinação Real do Trabalho ao Capital}

É importante ressaltar que o processo de modernização da agricultura, ao mesmo tempo em que submete a agricultura à lógica de valorização do capital, subordina formalmene o trabalho ao capital. Ou seja, o processo de modernização da agricultura, num mesmo movimento, subordina tanto as forças da natureza, quanto os trabalhadores à lógica de valorização do capital, à semelhança do que ele faz na indústria. Isto não significa que o processo seja contra o trabalhador: o processo de modernização, ao ser implementado, é a favor dos capitalistas. $^{11}$

A mecanização do corte de cana parece ser inexorável, dado a redução de custos e o aumento do poder de barganha que proporciona aos usineiros. Além de inexorável, a mecanização "beneficia", - perversamente -, os trabalhadores, no sentido de liberá-los de uma atividade estafante, que "encurta a vida"

Os trabalhadores assalariados rurais, quando elaboram suas expectativas da vida, deixam claro que "cortar cana não é trabalho de gente, é trabalho de bicho, de animal". Os trabalhadores assalariados rurais executam este trabalho por já não terem outro e por terem adquirido, no trabalho, uma especialização, que lhes garante, em péssimos niveis, sua reprodução

A mecanização do corte de cana representou para os usineiros, de um lado, o aumento do seu poder de barganha frente à, sempre presente, possibilidade de greve dos trabalhadores assalariados rurais, cortadores de cana, e, de outro, a liberação do processo de trabalho, no corte, da destreza e habilidade do trabalhador, 


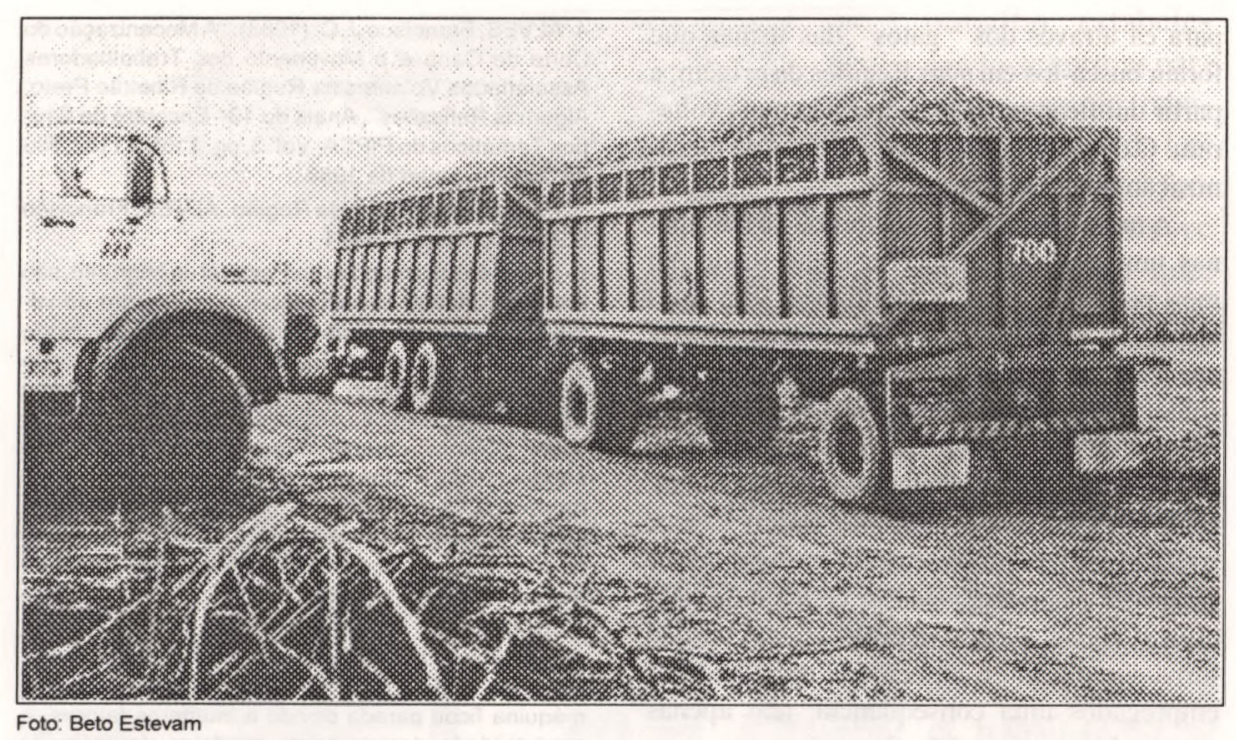

transformando a subordinação formal do trabalho ao capital, desses trabalhadores, em subordinação real. Para os trabalhadores, a mecanização do corte, reduziu o contingente de trabalhadores empregados no período da safra; reduziu o poder de pressão dos cortadores; reduziu o salário médio dos cortadores e avançou o processo de subordinação real do trabalho ao capital. Mas, de outro lado, possibilitou a tomada de consciência de que os tratoristas e operadores de máquinas são também assalariados rurais e, nesta fase da modernização da agricultura, passam a ser o contingente de trabalhadores com maior poder de barganha no processo de produção. Os trabalhadores perceberam que paralisando os cortadores de cana, os trabalhadores braçais, as usinas continuam operando, devido a forte mecanização, mas agora paralisando os tratoristas e operadores de máquina, não há como produzir,

Umas das áreas das usinas que também mais se modernizou, a partir do Pró-álcool, e mais especificamente a partir da década de 80 , foi o setor de recursos humanos, ou o departamento de pessoal das usinas. Os usineiros parceberam a necessidade de ter trabalhadores mais controlados pelas empresas, como forma de aumentar a produtividade do trabalho e diminuir as possibilidades de conflitos internos.

$\mathrm{Na}$ área de recursos humanos, uma das inovações principais foi a introdução de um sistema computadorizado de informações sobre os trabalhadores. Este é capaz de rapidamente fornecer uma ficha detalhada de cada trabalhador. Esta ficha detalhada, tem a finalidade de fornecer informações técnicas sobre cada trabalhador.

Segundo os dirigentes sindicais, o sistema fornece também outros tipos de informações, mais sigilosas, sobre: a participação dos trabalhadores nas greves da região; a proximidade deles com o sindicato; participação em piquetes, etc. Segundo trabalhadores e dirigentes sindicais, os usineiros da Região de Ribeirão Preto dispõem de uma "lista negra", com o nome de todos os trabalhadores com participação ativa em greves e piquetes, para impedir que estes consigam trabalho na Região. É claro que não foi possivel confirmar a existência de tais listas, nas usinas pesquisadas. Porém, é perceptível a dificuldade de vários trabalhadores, com participação em piquetes e na vida sindical, em conseguirem empregos nas usinas da Região. O que é um indício forte da existênbilidade de que elas sejam trocadas entre os usineiros.

As usinas declararam que este sistema é uma espécie de cadastro computadorizado, que fornece informações técnicas sobre cada trabalhador, ao início da safra, dado que a maior parte dos trabalhadores, registrados nas usinas, são contratados como safristas, isto é, têm contrato de 8 meses, tempo de duração da safra. Quando as usinas vão renovar os contratos ou contratar mais trabalhadores para a safra, o cadastro é consultado e fornece informações técnicas sobre o trabalhador. As informações técnicas disponíveis no sitema, de acordo com as usinas, são: produtividade média de cada trabalhador no corte de cana; produtividade do trabalhador na carpa e demais tratos culturais; assiduidade no trabalho; desleixo com equipamento, etc. Através destas informações a usina seleciona o seu contingente de trabalhadores de acordo com o tipo de trabalho a ser executado.

Através deste mecanismo de informações, foi possivel perceber, que as usinas, pós mecanização do corte, começam a ter preferência por um trabalhador mais polivalente, isto é, capaz de executar bem as distintas atividades existentes no setor agrícola das usinas. Como cia de tais listas, assim como é grande a possi- mostramos anteriormente, com a mecanização docorte, as usinas querem nivelar a contratação de trabalhadores para todo o ano, através do número necessário na entressafra. Isto significa que com a mecanização do corte não é mais necessário, na safra, contratar um grande número de cortadores de cana. Passa a ser necessário contratar apenas o número adequado de trabalhadores para colher a cana não colhida pelas máquinas e para realizar as demais operações, que ocorrem simultaneamente ao corte. Dessa forma, passa a ser interessante, para a usina, dispor tanto de trabalhadores bons de podão, como bons de enxada, de rastelo, etc.

\section{Modernização da Agricultura e Consequências para o trabalho Migrante}

A mecanização do corte, ao reduzir a demanda de trabalhadores e promover uma maior seleção, impõe a necessidade de reflexão sobre as possibilidades dos migrantes engajarem-se no mercado de trabalho do setor sucroalcooleiro. Começa a ficar patente o aumento do desemprego em plena safra; é grande o número de trabalhadores, mesmo os residentes na própria Região, que não conseguem emprego regular nas usinas. Percebe-se também a redução do número de migrantes sazonais na Região. Só têm emprego aqueles migrantes que já chegam à Região com contrato de trabalho garantido, isto é, aqueles que em suas Regiões de origem foram contactados pelos empreiteiros das usinas.

Se nas décadas de 1960 e 70 a contratação de migrantes nas regiões de origem era um mecanismo fundamental para a existência de um contingente de trabalhadores para a operação da usina, hoje, com a mecanização do corte, isto não é mais necessário, pois há abundância de trabalhadores nas próprias regiões produtoras. Além disto, é possível executar melhor seleção e preparação dos trabalhadores localmente, o que antes era feito no decorrer da safra, com a eliminação, dispensa daqueles que não se adaptavam às especificidades do trabalho.

Apesar da existência de trabalhadores na própria Região, algumas usinas ainda dão preferência à contratação de migrantes. Esta preferência é justificada fundamentalmente pelo aspecto disciplinar dos migrantes em relação ao trabalhadores locais. O migrante ao chegar e ficar alojado pela usina e na usina pode ser melhor controlado do que os trabalhadores locais que moram nas cidades. Nas greves o Movimento Sindical ainda tem dificuldades em conseguir organizar os migrantes para rea- 
lizarem a greve. Porém, em algumas greves, as de 1990 e 1991, a participação dos migrantes foi fundamental, mas esta só ocorreu quando foram incluídas algumas reivindicações específicas: melhoria dos alojamentos, melhoria na comida, redução do preço dos alojamentos e da comida, acerto de fim de safra antecipado, etc.

Outros usineiros não contratam migrantes e alegam que estes oneram a produção, devido a necessidade de construção de alojamentos e devido ao aspecto disciplinar. Pois muitos trabalhadores juntos, alegam eles, num mesmo espaço, torna-se um barril de pólvora, basta uma pequena centelha para provocar inúmeras confusões. Preferem a contratação de trabalhadores diretamente nas cidades próximas.

A contratação de migrantes se antes foi necessária para atender ao retardo temporal entre a expansão da cultura e a necessidade de trabalhadores, hoje isto não é mais necessário. Se a contratação de migrantes era importante devido ao aspecto disciplinar, a ocorrência de greves com a participação destacada de migrantes, inclusive com a mudança de postura do Movimento Sindical, desmistificou a imagem mais "dócil" e complacente do migrante. Isto deixa claro que é fundamental a mudança de postura dos empresários para com os trabalhadores, idependente de serem ou não residentes nas regiões produtoras. Ascrescente-se a isto que as usinas passaram a fazer maior seleção dos trabalhadres e o apecto disciplinar ocupa posição de destaque nas condições de contratação.

Neste sentido, considero que estamos chegando ao fim de um período e início de outro no mercado de trabalho rural do setor sucroalcooleiro no Estado de São Paulo, principalmente na Região de Ribeirão Preto. Percebo que a contratação de migrantes está se dando de forma bastante reduzida frente ao que já foi em passado recente, ainda que pese a falta de dados primários que a comprovem.

Esta constatação coloca em discussão duas questões fundamentais: a primeira é sobre o excedente de trabalhadores na Região canavieira de Ribeirão Preto, a segunda é sobre o fluxo migratório ainda existente de Regiões mais pobres, com superpopulação relativa, para Regiões mais ricas com maior demanda de trabalhadores.

Os usineiros, quando questionados sobre a redução do emprego provocado pela mecanização do corte, alegam que este é um problema social e deve ser resolvido pela sociedade em conjunto e não pelo setor sucro-alcooleiro. Esquecem a responsabilidade do setor em ter criado e incentivado este fluxo populacional. Os moradores residentes na Região são na sua grande maioria ex-migrantes, isto é, vieram e ficaram na Região devido à possibilidade de trabalho no setor. Grande parte começou a vir para cá através dos "gatos" das usinas que foram buscá-los em suas Regiões de origem, a partir daí ficaram na Região e não mais voltaram. O desemprego é a face perversa da mecanização do corte da cana.

A mecanização do corte tornou-se não apenas uma realidade concreta como tende, no meu ponto de vista, a ampliar-se. Em duas usinas do mesmo grupo, entrevistadas ainda em 1993, que atualmente têm $30 \%$ de sua colheita mecanizada, pretendem estendê-la para $85 \%$ e $95 \%$. O interesse pela mecanização cresce também em outras Regiões do Estado, como as Regiões de Piracicaba e Bauru. Cresce também o interesse do setor em passar a colher cana crua e não queimada. A colheita de cana crua é viável apenas mecanicamente, o que torna a redução do número de trabalhadores empregados uma consequência, não apenas provável, como inexorável.

Dado esta tendência acredito que o problema só poderá ser equacionado através de ações nas Regiões de origem e de destino destes trabalhadores. Nas Regiões de origem são necessárias medidas para a intensificação da demanda de trabalhadores, quer através da introdução de culturas agricolas mais demandantes de trabalhadores, quer através da Reforma Agrária nestas Regiões, que dê condições de sobrevivência aceitável aos pequenos produtores. Nas Regiões de destino a solução do desemprego depende mais de mudanças na estrutura do emprego, que envolve o crescimento econômico urbano/industrial e na requalificação de trabalhadores para ocuparem os novos postos de trabalho criados pela mecanização do corte, que requer um número maior de tratoristas, operadores de máquinas agricolas, mecânicos, motoristas, etc. Porém em ambas as Regiões é necessário a melhoria das condições de trabalho, que passa por mudanças no processo de trabalho e pelo cumprimento dos acordos e legislação trabalhista.

* Francisco Alves é Prof. do Depto. de Engenharia de Produção da Universidade Federal de São Carlos.

\section{NOTAS}

1- ALVES, Francisco (1991). "Modernização da Agricultura e Sindicalismo: As Lutas dos Trabalhadores Assalariados Rurais da Região Canavieira de Ribeirão Preto", Tese de Doutoramento, I.E.JUNICAMP Campinas, SP. Esta tese è a referência básica do artigo.

2- Este sistema ainda é bastante utilizado em algumas áreas do nordeste, principalmente nas áreas de terreno mais acidentado, onde a cana é primeiro transportada em lombo de burro, pelos cambiteiros, $e$ depois é atirada na carroceria dos caminhões pelos carregadores, que dependendo da distância, também transportam a cana colhida até os caminhões. 3-Uma carregadeira substitui, em média, cerca de 30 homens, durante a safra. GRAZIANO DASILVA (1980) "Progresso Técnico e Relações de Trabalho na Agricultura Paulista", Tese de Doutoramento, IFCH/ UNICAMP, pg. 147.
4-ALVES, Francisco J.C. (1988). "AMecanização do Corte de Cana e o Movimento dos Trabalhadores Assalariados Volantes na Região de Ribeirão Preto: Algumas Reflexões", Anais do $13^{\circ}$ Encontro de Grupos Temáticos do PIPSA, Vol. 3, pg. 1165 a 1182, Rio de Janeiro, junho de 1988.

5- Fala de um usineiro da Região. ALVES, Francisco (1988), op. cit., pg. 1171

6-Segundo informaçōes da Pastoral do Migrante, são cerca de 20.000 trabalhadores que migram anualmente do norte de Minas Gerais; Sul da Bahia; Norte do Paraná e outros Estados do Nordeste, para o corte da cana em São Paulo. É necessário ter claro que há enorme dificuldade na obtenção de dados concretos sobre esse movimento migratório, dado que sảo trabalhadores vindos de uma vasta Região, cujo número varia, de ano para ano, devido a um conjunto de variáveis: seca nas Regiōes de origem; dificuldades de trabalho nas Regiōes de destino; condiçōes de moradia e baixos salários, etc.

7- GRAZIANO DA SILVA (1989), ALVES (1988), respectivamente. Trata-se de produtividade média por hora, onde estão incluídos o tempo em que a máquina ficou parada devido a inúmeros fatores. A produtividade destes novos modelos de máquina atinge até 200 toneladas por hora efetiva de trabalho sem interrupçōes.

8- Dados de usinas visitadas entre 1988 e 1989 Observaçōes de campo do autor

9- GRAZIANO DA SILVA (1989), op. cit. pg. 51 , referindo-se a trabalhadores de KAGEYAMA et alli (1981).

10- BERTOLLO, Evandro (1990). "Viabilidade Econômica da Mecanização do Corte de Cana", Relatório Parcial de Iniciação Cientifica, apresentado ao CNPq em junho de 1990, Departamento de Engenharia de Produção, UFSCar, orientação do autor.

11-MARX, Karl. "Capital y Tecnologia", manuscritos de 1861-1863 al cuidado de Piero Bolchini, Terra Nova, México, 1980, pg. 136. Tradução do autor.

$$
\text { * } * \text { * }
$$

DEMOCRATIZAÇÃO DOS MEIOS DE COMUNICAÇÃO

É o tema do $n^{\circ} 58$ da

\section{REVISTA proposta}

Editada trimestralmente pela FASE, a revista proposta reúne, a cada número educadores e profissionais para elaborar, refletir e sistematizar questões pelos movimentos sociais, oferecendo-Ihes elementos para seu avanço na compreensão das realidades nas quais estão inseridos.

\section{ASSUMA ESTA proposta!}

Assinaturas e números avulsos, disque:

(021)286-1598 